\title{
Extractive Spectrophotometric Determination of Trace Hg (II) in Eye Drops and Ayurvedic Medicines Using Pyridine 2-Carboxaldehyde 2-Hydroxybenzoylhydrazone
}

\author{
Murli N. Bale,* Arun D. Sawant,* Hamid Shaikh,** and Dipak J. Garole***† \\ * Inorganic Chemistry Division, The Institute of Science, Madam Cama Road, Mumbai-400020, Maharashtra, \\ India \\ ** SABIC Polymer Research Center (SPRC), Chemical Engineering Department, King Saud University, P. O. \\ Box 800, Riyadh 11421, Saudi Arabia \\ *** Directorate of Geology \& Mining, Government of Maharashtra, Nagpur-440010, Maharashtra, India
}

\begin{abstract}
A rapid, simple and selective spectrophotometric method was developed for the determination of mercury (II) by using reagent, Pyridine-2-carboxaldehyde 2-hydroxybenzoylhydrazone (PAHB). The reagent is highly selective and sensitive and it forms yellow coloured complex with mercury (II) having composition 1:2 $(M: L)$ in alkaline $\mathrm{pH}$ range. Absorption of coloured complex in toluene is measured with reagent as blank at גmax $385 \mathrm{~nm}$. The beers law is obeyed in concentration range from 0.5-5.8 ppm for mercury (II)Pyridine-2-carboxaldehyde 2-hydroxybenzoylhydrazone complex and it was evaluated from Ringboms plot. Molar absorptivity and Sandells sensitivity value for mercury (II)- Pyridine-2-carboxaldehyde 2-hydroxybenzoylhydrazone complex are $5.87 \mathrm{n} \mathrm{cm}^{-2}$ and $3.14 \times 104 \mathrm{l} \mathrm{mol}^{-1} \mathrm{~cm}^{-1}$, respectively. The sensitivity of the developed method was checked in presence of various foreign ions. The method is successfully applied for mercury (II) determination in binary, synthetic mixtures and real pharmaceutical samples. The accuracy and reliability of method was verified by $A A S$.
\end{abstract}

Keywords: Mercury, solvent extraction, Pyridine-2-carboxaldehyde 2-hydroxybenzoylhydrazone, Pharmaceuticals, Ayurvedic sample analysis

\section{Introduction}

Mercury is one of the most hazardous heavy metal in the nature and its toxicity is well documented in the literature. It exists in three valence state with trace and ultratrace amounts ${ }^{1}$. A chronic exposure to mercury can result in several diseases, including, acrodynia (pink disease), neurological diseases, Hunter-Russell syndrome, mad hatters disease, leukaemia and Minamata disease ${ }^{2-7}$. The mercury and its derivatives exist in several forms which readily react with organic and inorganic ligands to form various complexes. Methyl mercury is the most common form produced by natural processes that accumulates in human body through the food chain. It is to worth mention that the determination of low concentration mercury is a vital task. Therefore, considerable efforts have been made to develop accurate, fast and reliable methods for the determination of mercury and its derivatives. Various analytical methods and reagents was used for mercury determination that includes colorimetry, atomic absorption spectroscopy (AAS), atomic emission spectroscopy (AES), cold vapour atomic absorption spectroscopy (CVAAS), cold vapour atomic fluorescence spectroscopy (CVAFS), polarography, neutron activation analysis, gas chromatography (GC) and high-performance liquid chromatography (HPLC) $)^{8-17}$. Similarly, reagents like 1-(1H-benzimidazol-2-yl) guanidine (GIB), (Sensing of mercury(II) using 1-(1H-benzimidazol-2-yl) guanidine as chromophore ${ }^{18}$, Poly(2-aminothiazole) (Synthesis of Poly(2-aminothiazole) for Selective Removal of $\mathrm{Hg}$ (II) in Aqueous Solutions ${ }^{19}$, 2-octylaminopyridine (2-OAP), Extraction and separation of mercury(II) from succinate media with high molecular weight amine as an extractant $^{20}$, have been explored recent time. Due to increasing recognition that alternative medicine such as Ayurveda, Unani, and Homeopathy etc. are non-toxic, cheap and have less side effect the demand of these products are increasing continuously in both developing and developed countries ${ }^{21}$. Specifically, the Ayurveda product has emerged as the new growth frontier for medicine sector in India. Despite of this, very few systematic studies was carried out to know the mercury contents and performance of particular Ayurveda product. Recently, Chandrasekhar et al. used high molecular weight amines for the determination of mercury in ayurvedic medicine ${ }^{20}$. The chromogenic reagent Pyridine-2-carboxaldehyde 2-hydroxybenzoylhydrazone is good ligand that can form metal complexes with various ions. In our previous study we have determined the uranium (VI) by using this reagent ${ }^{22}$, To further validate the performance of this reagent, herein we utilized it for the determination of mercury (II) in ayurvedic medicine and eye drops samples. To the best of our knowledge, no analytical study has been carried out for the determination of mercury from these samples by using this reagent. The various parameters that affect the performance of the formed complex were also studied in detail. 
Although, mercury has been used as a skin bleaching agent and as a preservative in pharmaceutical and cosmetic products for many years.Mercury is used as a preservative (e.g., thimerosal, as an antifungal and antiseptic agent) in many drug products such as vaccines (influenza, hepatitis B, DPT), ointments (eye ointments, haemorrhoid ointments), contact-lens solutions and ear, eye solutions. Currently mercury can be present in pharmaceutical products even when it is not listed on the label or on the product information leaflet. It is usually introduced as a preservative or anti-microbial in the form of thimerosal. Thimerosal or merthiolate is a derivative of thiolsalicylate where ethyl-mercury is attached though the sulfur or the thiol group, and its half molecular weight belongs to mercury. Thimerosal has been and is used in a variety of drug products especially for local use, because of its antiseptic properties. These products include vaccines, cosmetics, eye, ear, nasal drops and saline solutions. In the human body mercury is metabolized or degraded in ethylmercury $\left(\mathrm{C}_{2} \mathrm{H}_{5} \mathrm{Hg}^{+}\right)$ and thiosalicylate (Center for Biologics Evaluation and Research 2008). In contrast, some forms of mercury are relatively non-toxic and have been used as medicines e.g. for the treatment of syphilis ${ }^{23}$. Due to human activities major amount of mercury enters into the environment through chlor-alkali industries, plastic industries, electrical, paint and pharmaceutical industries ${ }^{2,24-28}$. In addition, Mercury compounds are used as catalysts, fungicides, pesticides and also add mercury to the environment via the natural resources like water, food and igneous rocks, in particular granite for living organisms and additionally increases the danger of mercury exposure, even at trace levels ${ }^{29,30}$. The environmental contaminants such as $\mathrm{Pb}^{2+}, \mathrm{Cd}^{2+}$ and $\mathrm{Hg}^{2+}$ have been exploited by a number of research groups ${ }^{31}$. All these findings cause great concern regarding public health, demanding an accurate determination of this metal ion at trace and ultra-trace levels. Methods for mercury determination include colorimetry, atomic absorption spectroscopy (AAS), atomic emission spectroscopy (AES), cold vapor atomic absorption spectroscopy (CVAAS), cold vapor atomic fluorescence spectroscopy (CVAFS), polarography, potentiometric titration, neutron activation analysis, gas chromatography (GC) and high-performance liquid chromatography $(\mathrm{HPLC})^{8-11}$. The assessment of environmental impact, predictions of mobility of mercury in the environment or evaluation of concentrations in removal technologies require the speciation of the element. For this purpose, inorganic and organic mercury species have been separated by GC or HPLC $^{32,33}$ and references therein. GC techniques require long clean-up procedures, and several organomercury compounds are thermally stable or strongly retained by the columns 26 . In contrast, HPLC techniques are simpler, but detection systems as, for example, mass spectrometry (MS), inductively coupled plasma techniques (ICP-AES, ICP-MS), etc., require costly instrumentation ${ }^{34,35}$. A recent literature on the analytical applications of the entitled reagent Pyridine-2-carboxaldehyde 2-hydroxybenzoylhydrazone has revealed no study on the use of the reagent for mercury (II) determination. We report herein a simple and selective extraction procedure for mercury (II) with Pyridine-2-carboxaldehyde 2-hydroxybenzoylhydrazone. The method permits separation of mercury (II) from other toxic metals and has been used to separate and determine mercury (II) in synthetic mixture, ayurvedic medicine and eye drops samples.

\section{Reagents and chemicals}

\section{Experimental}

All reagents were analytical grade and used as received without further purification. A standard stock solution of mercury (II) $\left(5 \mathrm{mg} \mathrm{mL}^{-1}\right)$ was prepared by dissolving calculated amount of mercury chloride (Merck) in $5 \mathrm{~mL}$ concentrated hydrochloric acid and diluted to $1000 \mathrm{~mL}$ with distilled water and standardized with 1-(2-pyridylazo)-2-napthol (PAN) method ${ }^{36}$. The working solution was prepared by appropriate dilution of stock solution with distilled water. Buffer solution ( $\mathrm{pH} 9.0$ ) was prepared by dissolving $67.5 \mathrm{~g}$ of ammonium chloride (Merck) in $570 \mathrm{~mL}$ concentrated liquor ammonia and diluted to $1000 \mathrm{~mL}$ with distilled water. A $1 \%(\mathrm{~W} / \mathrm{v}$ ) solution of Pyridine-2-carboxaldehyde 2-hydroxybenzoylhydrazone (PAHB) was prepared by dissolving in Dimethy formamide (DMF). All the standard solutions of metal ions used to study the effect of diverse ions were prepared by dissolving weighed quantity of their salts in concentrated acids and then diluted with distilled water. The solution of anions was prepared by dissolving their respective alkali metal salts in distilled water. The double distilled water was used throughout the experiment.

\section{Apparatus}

A digital $\mathrm{pH}$ meter was used for $\mathrm{pH}$ measurement (Elico $\mathrm{pH}$ meter, model Li-120). Meddler analytical single pan balance model having accuracy $0.001 \mathrm{~g}$ was used for weighing operation. A Shimadzu UV-Visible double beam spectrophotometer 2400 with $1 \mathrm{~cm}$ quartz cell used for absorbance measurement.

\section{General extraction and determination procedure for mercury (II)}

To $1 \mathrm{~mL}$ aliquot of aqueous solution containing $50 \mu \mathrm{g}$ of mercury(II), few $\mathrm{mL}$ of distilled water was added and $\mathrm{pH}$ was adjusted to required value by dilute solution of nitric acid and sodium hydroxide. The solution was diluted to $10 \mathrm{~mL}$ and was equilibrated for 1 min with $10 \mathrm{~mL}$ of chloroform and $1 \mathrm{~mL}$ of $1 \%$ PAHB in DMF. The two phases were collected separately in $10 \mathrm{~mL}$ of volumetric flasks. An appropriate volume of the 
phase was taken and evaporates to dryness. Subsequent decomposition with aqua-regia followed by hydrochloric acid was carried out before it was finally extracted in distilled water. The mercury (II) in each phase was determined by 1-(2-pyridylazo)-2-napthol (PAN) as per reported method ${ }^{36}$.

\section{Results And Discussion}

\section{Formation of complex and its spectral characteristics}

As shown in Fig.1 formation of possible complex with Pyridine-2-carboxaldehyde 2-hydroxybenzoylhydrazone (PAHB) in DMF. It is extracted in toluene and analysed for UV measurement. It is observed that this complex shows the maximum absorbance at $385 \mathrm{~nm}$. The spectra of the reagent blank and colored complex are shown in Fig. 2.

\section{Study of extraction efficiency as a function of $p H$}

The extraction efficiency of metal ion is highly depending on the $\mathrm{pH}$ of the medium. To study this effect, extraction of very low concentration of mercury $(50 \mu \mathrm{g})$ was carried out at $\mathrm{pH}$ varying from 1.0 to 11.0 using toluene which contains $1 \mathrm{~mL}$ of $1 \%$ PAHB in DMF. The quantitative extraction of mercury (II) between pH 8.5 to 10.0 is shown in Fig. 3. The result indicates that the quantitative extraction of mercury (II) are occurs in the $\mathrm{pH}$ range 8.8-10.0. The extraction is found to be incomplete above and below to this range of $\mathrm{pH}$. Hence pH 9.0 was selected for further study.

\section{Effect of solvents}

A variety of solvents were tried to study their suitability and adequacy for the extraction of mercury(II). Benzene, toluene, xylene and 1,2-dichlorobenzene gave quantitative extraction of mercury(II) with $99.9 \%$ where as in other solvents the extraction of mercury(II) was incomplete such as chloroform (86\%), 1,2-dichloroethane $(84.2 \%)$, tetrachloroethane $(65.9 \%)$, isoamyl acetate $(63.5 \%)$, ethyl acetate $(63.5 \%)$, carbon tetrachloride (45.1\%) and isobutyl methyl ketone (36.2\%). Out of the above solvents which gave quantitative extraction of mercury(II) toluene was preferred as the phase separation was fast, clear and emulsion was not observed.

\section{Effect of PAHB concentration}

The concentration of PAHB in DMF was varied within the range $2.07 \times 10^{-4}$ to $2.90 \times 10^{-3} \mathrm{~mol} \mathrm{~L}^{-1}$. The reagent was added into $50 \mu \mathrm{g} \mathrm{mL}^{-1}$ of mercury (II) ion solution. Absorbance was measured according to the developed procedure. It was observed that $1 \mathrm{~mL}$ of $1 \%$ reagent concentration was required for full colour development. There is no significant change in the absorption with excess of the reagent concentration (Fig. 4).

\section{Effect of shaking time}

The optimum shaking time of $30 \mathrm{sec}$ was determined by varying the shaking time from $10 \mathrm{sec}$ to 180 sec. prolonged shaking has no adverse effect on the extraction of mercury (II). Hence, a shaking time of 60 seconds was selected for subsequent experiment.

\section{Effect of colour stability of complex}

The colour stability was studied at room temperature by measuring the absorbance at regular time intervals. The absorbance of mercury (II)-PAHB complex in toluene was stable for 6 days.

\section{Beers law, sensitivity, precision and accuracy of the method}

The absorbance of the extracted species was a linear function of mercury (II) concentration in the range of $0.5-5.8 \mu \mathrm{g} \mathrm{mL}^{-1}$ at $385 \mathrm{~nm}$. The optimum working range, obtained from Ringbom's plot was found to be $0.30-0.81 \mu \mathrm{g} \mathrm{mL}^{-1}$ that confirms the Beers range (Fig. 5). Sandells sensitivity of the method was found to be $5.87 \mathrm{ng} \mathrm{cm}^{2}$, while molar absorptivity was $3.41 \times 10^{4} \mathrm{~mol}^{-1} \mathrm{~cm}^{-1}$. The precision and accuracy of the method were determined by analysing the solutions containing known amount of mercury (II). The average of 10 determinations of $50 \mu \mathrm{g}$ of mercury (II) was $49.95 \mu \mathrm{g}$ with standatd deviation 0.28 and variance 0.08 . Variation from mean at $95 \%$ confident limit was $49.95 \pm 0.20$.

\section{Composition of the complex}

The composition of complex was studied in the excess of reagent solution by the mole-ratio and Job's methods (Fig. 6). A break at a 1:2 (M:L) mole ratio suggested the formation of complex where $\mathrm{M}=\mathrm{Hg}(\mathrm{II})$ and $\mathrm{L}=$ PAHB under the given conditions (Fig. 7).

\section{Effect of foreign ions}

The selectivity of the method was investigated by the determination of $50 \mu \mathrm{g} \mathrm{mL} \mathrm{L}^{-1}$ of mercury(II) in the presence of number of cations and anions within a relative error of $\pm 2 \%$. The obtained results were presented in Table 1. The interference of cations was removed by using masking agent, thus making the method more selective. 


\section{Applications \\ Separation of mercury (II) from associated metal ions}

PAHB is used for the separation and determination of mercury (II) from associated metal ions containing $\mathrm{Cr}(\mathrm{VI}), \mathrm{Fe}(\mathrm{III}), \mathrm{Zn}(\mathrm{II}), \mathrm{Cd}(\mathrm{II}), \mathrm{Tl}(\mathrm{I}), \mathrm{Bi}(\mathrm{III})$ and $\mathrm{Pb}(\mathrm{II})$ by its extraction with recommended procedure. (Table 2).

\section{Determination of Mercury (II) from synthetic mixtures}

Several synthetic mixtures of varying compositions containing $50 \mu \mathrm{g}$ of mercury (II) and associated metal ions of known concentration were added, followed by respective masking reagents. Extraction of mercury (II) was analyzed by employing the recommended procedure (Table 3 ). The results obtained were in perfect and good agreement with the amount added.

\section{Determination of mercury (II) from Eye drops}

Mercury (II) was extracted and determined from eye drops samples such as Soframycine, Pyrimon and Vanmycetin. A known amount of sample containing mercury was taken separately in $25 \mathrm{~mL}$ volumetric flasks. The flasks were placed on steam bath, evaporated to dryness and mass were extracted with $5 \mathrm{~mL}$ of distilled water with few drops of $\mathrm{HCl}$ an $\mathrm{HNO}_{3}$. The flask was further heated on steam bath for 30 min. Air was blow in to the flasks for 2-3 min to expel amino oxides. After cooling the mixture, $10 \mathrm{~mL}$ distilled water and $2 \mathrm{~mL}$ of $5 \%$ potassium dichromate were added and finally dilute up to the mark. A definite amount of the solution was used to extract and determine mercury by recommended procedure. The result was confirmed by standard method (Table 4).

\section{Determination of mercury (II) from Ayurvedic medicines}

The proposed method was applied for determination of mercury (II) in ayurvedic medicine samples such as Ras Sindur (used to improve immunity, strength etc.) and Siddha Makardhwaj (used for rejuvenation, convalescent and aphrodisiac therapy). A known amount of sample was dissolved in $5 \mathrm{~mL}$ aqua-regia. The organic matter was destroyed by treatment with $2.0 \mathrm{~mL}$ of conc. HClO4. The solution was evaporated to moist dryness. The residue was dissolved in hot dil $\mathrm{HCl}$ and filtered through whatmann filter paper (No.1). The filtrate was diluted to $250 \mathrm{~mL}$ with distilled water. An aliquot of mercury (II) containing solution was analyzed by recommended procedure. The results were good agreement with those of standard PAN method (Table 5).

\section{Conclusion}

The synthesised reagent Pyridine-2- carboxaldehyde 2-hydroxybenzoylhydrazone (PAHB) has been proved to be highly sensitive for extraction and spectrophotometric determination of mercury(II). It is observed to be applicable for the determination of mercury(II) in binary, synthetic mixtures and various real sampls with satisfactory results. Sailent futures; (i) trace concentration of mercury(II) $\left[50 \mu \mathrm{g} \mathrm{mL}^{-1}\right]$ can determined by the reagent. (ii) The developed extraction procedure is a single stage. (iii) The yellow colourd complex is stable for 6 days. (iv) Pyridine-2- carboxaldehyde 2-hydroxybenzoylhydrazone (PAHB) form complex with mercury(II) in alkaline medium and extracted in toluene probable stoichiometry of extracted species as 1:2 (M:L). (v) The present method does not face the problem of interference due to foreign ions to greater extent. (vi) The developed method is simple, reproducible, rapid, selective and used for separation and determination of mercury(II) in real samples and synthetic mixtures of associated metal ions.

\section{References}

[1]. R. A. Gayer, "Toxicological Effects of Methyl Mercury" 2000, National Academy Press, Washington.

[2]. Agency for Toxic substance and Disease Registry ATSDR, “Toxicology profile for mercury" 1999, Public Health service, Atlanta.

[3]. M.E. Stone, M.E. Cohen, and L. Liang, Dent. Mater., 2003, 19, 675.

[4]. J. E. Fergusson, "The Heavy Elements: Chemistry, Environmental Impact and Health Effects" 1990, Pergamon Press, Oxford.

[5]. M. O. Amdur, J. Doull, and C. D. Klaassen, "Casarett and Doull's Toxicology: The Basic Science of Poisons (4th ed.)" 1993, McGraw-Hill, New York.

[6]. K. Janicki, J. Dobrowolski, and K. Krasnicki, Chemosphere, 1987, 16, 253.

[7]. Y. Kinjo, S. Akiba, and N. Yamaguchi, J. Epidemiol., 1996, 6, 134.

[8]. J.E. Parkin, J. Chromatogr. A., 1986, 370, 210.

[9]. R. D. Wilken, Fresenius J. Anal. Chem., 1992, 342, 795.

[10]. M. C. Canela, W. F. Jardim, and J. J. R. Rohwedder, J. Automatic Chem., 1996, 18, 193.

[11]. C. Sarzanini, G. Sacchero, M. Aceto, O. Abollino, and E. Mentasti, J. Chromatogr., 1992, 626, 151.

[12]. V. L. Dressler, C. M. M. Santos, F. G. Antes, F. R. S. Bentlin, D. Pozebon, and E. M. M. Flores, Food Anal. Methods, 2012, 5 , 505.

[13]. P. N. Kumar Reddy, G. T. Reddy, K. Ms. Sangita, A. V. R. Reddy, S. N. Parveen, and N. C. G. Reddy, Der Pharmacia Lettre, 2015, 7, 292.

[14]. R. F. Martı'nez, I. Rucandio, I. Go' mez-Pinilla, F. Borlaf, F. Garc1', and M. T. Larrea, J. Food Compos. Anal., $2015,38,7$.

[15]. M. M. S. Junior, L. O. B. Silva, D. J. Leao, W. N. L. dos Santos, B. Welz, and S. L. C. Ferreira, Food Control, 2015, $47,623$.

[16]. J. Ali, M. Tuzen, and T. G. Kazi, Water Air Soil Pollut., 2016, 227, 170.

[17]. I. L. S. Almeida, M. D. R. Oliveira, J. B. B. Silvac, and N. M. M. Coelho, Microchem. J., 2016, $124,326$.

[18]. C. N. Sundaresan, D. K. Singh, and A. Sunil, Journal of Advanced Chemical Sciences, 2016, 2, 195. 
[19]. X. Wang, L. Pengfei, H. Zou, Y. Li, L. Xiaoyan, and Y. Liao, Ind. Eng. Chem. Res., 2016, 55, 4911.

[20]. C. P. Mane, S. V. Mahamuni, A. P. Gaikwad, R. V. Shejwal, S. S. Kolekar, and M. A. Anuse, J. Saudi. Chem. Soc., 2015, 19, 46.

[21]. A. N. Kalia, "Text Book of Industrial Pharmacognosy" 2005, Oscar publication.

[22]. M. N. Bale and A. D. Sawant, J. Radioanal. Nucl. Chem., 2001, 247, 531.

[23]. V. P. Kudesia, "Toxicity of metals in Air Pollution" 1988, Pragati Prakashan, Meerut.

[24]. A. K. De, "Second Environmental Chemistry" 1989, Wiley Eastern Limited, New Delhi.

[25]. C. D. Klaassen, "Casarette and Doull's Toxicology" 2001, McGraw-Hill, New York.

[26]. P. O’Neil, "Second Mercury in Environmental Chemistry" 1995, Chapman and Hall, London.

[27]. B. B. Petkovic, R. M. Simonovic, and R. J. Micic, J. Ana. Chem., 2007, 62, 697.

[28]. W. Qin, C. Guohua, Y. Jinhu, and D. Bin, Ana. Lett. 2003, 36, 627.

[29]. M. S. Tehrani, H. H. Moghaddam, M. H. Givianrad, and P. A. Anal, Bioanal. Chem. 2006, 386, 1407.

[30]. J. L. Manzoori, M. H. Sorouaddin, and A. M. Hajishabani, J. Anal. Atom. Spectram., 1998, 13, 305.

[31]. T. C. Hutchinso and K. M. Meema, “Lead, Mercury, Cadmium and Arsenic in the Environment (Scope. 31)” 1987, Pergamon Press, Oxford.

[32]. C. F. Harrington, Trends Anal. Chem., 2000, 19, 167.

[33]. E. Ramalhosa, S. Río-Segade, E. Pereira, C. Vale, and A. Duarte, Anal. Chim. Acta, $2000448,135$.

[34]. S. Río-Segade and C. Bendicho, Talanta, 1999, 48, 477.

[35]. W. Langseth, Anal. Chim. Acta, 1986, 185, 249.

[36]. S. Shibata, Anal. Chim. Acta. 1961, 25, 348.

Table 1 Effect of foreign ions on the extraction of $50 \mu \mathrm{g}$ mercury (ii) at $\mathrm{pH} 9.0$ from $0.5 \mathrm{ml}$ of $1 \%$ PAHB in DMF extracted in toluene

\begin{tabular}{|c|c|c|c|}
\hline Foreign Ion & $\begin{array}{l}\text { Tolerance } \\
\text { limit (mg) }\end{array}$ & Foreign Ion & $\begin{array}{l}\text { Tolerance } \\
\text { limit }(\mathrm{mg})\end{array}$ \\
\hline $\operatorname{Li}(\mathrm{I})$ & 10.0 & $\mathrm{~F}^{-}$ & 20.0 \\
\hline $\mathrm{Mg}(\mathrm{II})$ & 10. & $\mathrm{Cl}^{-}$ & 20.0 \\
\hline $\mathrm{Al}(\mathrm{III})$ & 2.50 & $\mathrm{Br}^{-}$ & 20.0 \\
\hline $\mathrm{V}(\mathrm{V})$ & 3.50 & $\mathrm{I}^{-}$ & 0.30 \\
\hline $\mathrm{Cr}(\mathrm{VI})$ & 10.0 & $\mathrm{SO}_{3}{ }^{2-}$ & 0.40 \\
\hline $\mathrm{Fe}(\mathrm{III})$ & 2.00 & $\mathrm{SO}_{4}{ }^{2-}$ & 20.0 \\
\hline $\mathrm{Zn}(\mathrm{II})$ & $5.0^{*}$ & $\mathrm{~S}_{2} \mathrm{O}_{7}{ }^{2-}$ & 20.0 \\
\hline As(III) & 10.0 & $\mathrm{~S}_{2} \mathrm{O}_{8}{ }^{2-}$ & 20.0 \\
\hline $\mathrm{Se}(\mathrm{IV})$ & 10.0 & $\mathrm{NO}_{2}{ }^{-}$ & 20.0 \\
\hline $\mathrm{Zr}(\mathrm{IV})$ & 10.0 & $\mathrm{NO}_{3}{ }^{-}$ & 20.0 \\
\hline Mo(VI) & 10.0 & $\mathrm{ClO}_{3}^{-}$ & 20.0 \\
\hline $\mathrm{Ru}(\mathrm{III})$ & 4.50 & $\mathrm{BrO}_{3}{ }^{-}$ & 20.0 \\
\hline $\mathrm{Rh}$ (III) & 10.0 & $\mathrm{IO}_{3}{ }^{-}$ & 20.0 \\
\hline $\mathrm{Pd}(\mathrm{II})$ & 9.0 & $\mathrm{SCN}^{-}$ & 13.5 \\
\hline $\mathrm{Cd}(\mathrm{II})$ & $2.00^{\mathrm{a}}$ & Acetate & 20.0 \\
\hline $\mathrm{Sb}$ (III) & 5.0 & Oxalate & 20.0 \\
\hline $\mathrm{Ba}$ (II) & 8.20 & Citrate & 20.0 \\
\hline $\mathrm{W}(\mathrm{VI})$ & 10.0 & Tartarate & 20.0 \\
\hline $\mathrm{Pt}(\mathrm{IV})$ & 10.0 & Urea & 20.0 \\
\hline $\mathrm{Au}(\mathrm{III})$ & 9.0 & Thiourea & 0.20 \\
\hline $\mathrm{Tl}(\mathrm{I})$ & 0.45 & & \\
\hline $\mathrm{Pb}$ (II) & $2.0^{\mathrm{b}}$ & & \\
\hline $\mathrm{Ce}(\mathrm{IV})$ & 0.75 & & \\
\hline Th(IV) & 1.20 & & \\
\hline $\mathrm{U}(\mathrm{VI})$ & 0.70 & & \\
\hline
\end{tabular}

a. Masked by KNa-Tartarate

b. Masked by $\mathrm{Na}_{2} \mathrm{SO}_{4}$

Table 2 Separation of mercury(II) from associated metal ions

\begin{tabular}{|l|l|l|}
\hline $\begin{array}{l}\text { Binary mixture composition } \\
(\mu \mathrm{g})\end{array}$ & $\%$ Recovery $^{\mathrm{a}}$ & Estimation Procedure \\
\hline $\mathrm{Hg}(\mathrm{II}), 50 ;$ & 99.9 & Diphenylcarbazide \\
$\mathrm{Cr}(\mathrm{VI}), 500$ & 99.8 & \\
\hline $\mathrm{Hg}(\mathrm{II}), 50 ;$ & 99.7 & Thiocynate \\
$\mathrm{Fe}(\mathrm{III}), 50$ & 99.6 & \\
\hline $\mathrm{Hg}(\mathrm{II}), 50 ;$ & 99.8 & 4-(2-Pyridylazo)resorcinol \\
$\mathrm{Zn}(\mathrm{II}), 100$ & 99.5 & \\
\hline $\mathrm{Hg}(\mathrm{III}), 50 ;$ & 99.6 & 4-(2-Pyridylazo)-2-napthol \\
$\mathrm{Cd}(\mathrm{II}), 100$ & 99.6 & \\
\hline $\mathrm{Hg}(\mathrm{II}), 50 ;$ & 99.9 & 4-(2-Pyridylazo)resorcinol \\
$\mathrm{Tl}(\mathrm{I}), 500$ & 99.8 & \\
\hline $\mathrm{Hg}(\mathrm{II}), 50 ;$ & 99.7 & Pyridine-2-carboxaldehyde \\
$\mathrm{Bi}(\mathrm{III}, 50$ & 99.9 & 2-hydroxybenzoylhydrazol \\
\hline $\mathrm{Hg}(\mathrm{II}), 50 ;$ & 99.7 & Pyridine-2-acetaldehyde \\
$\mathrm{Pb}(\mathrm{II}), 100$ & 99.7 & salicylolhydrazone \\
\hline
\end{tabular}

a. Average of five determinations 
Table 3 Determination of mercury(II) from synthetic mixtures

a. Average of five determinations

\begin{tabular}{|l|l|}
\hline Synthetic mixture composition $\quad(\mu \mathrm{g})$ & \% Recovery $^{\mathrm{a}}$ \\
\hline $\mathrm{Hg}, 50 ; \mathrm{Fe}, 50 ; \mathrm{Cr}, 500$ & 99.9 \\
\hline $\mathrm{Hg}, 50 ; \mathrm{Sb}, 200 ; \mathrm{As}, 200$ & 99.8 \\
\hline $\mathrm{Hg}, 50 ; \mathrm{Au}, 200 ; \mathrm{Pd}, 200$ & 99.9 \\
\hline $\mathrm{Hg}, 50 ; \mathrm{Tl}, 100 ; \mathrm{Fe}, 50$ & 99.7 \\
\hline $\mathrm{Hg}, 50 ; \mathrm{Sb}, 200 ; \mathrm{Se}, 500$ & 99.8 \\
\hline $\mathrm{Hg}, 50 ; \mathrm{Au}, 200 ; \mathrm{Cr}, 500$ & 99.9 \\
\hline
\end{tabular}

Table 4 Determination of mercury(II) in eye drops

\begin{tabular}{|l|l|l|l|}
\hline Sample & $\begin{array}{l}\text { Certified value of mercury } \\
(\mu \mathrm{g} / \mathrm{ml})\end{array}$ & $\begin{array}{l}\text { Mercury found by PAHB } \\
\operatorname{method~}^{\mathrm{a}}(\mu \mathrm{g} / \mathrm{ml})\end{array}$ & $\begin{array}{l}\text { Mercury found by PAN } \\
\operatorname{method}(\mu \mathrm{g} / \mathrm{ml})\end{array}$ \\
\hline $\begin{array}{l}\text { Soframucine } \\
\text { [Roussel India Ltd] }\end{array}$ & 12.64 & 12.58 & 12.62 \\
\hline $\begin{array}{l}\text { Pyrimon } \\
\text { [FDC Ltd., India] }\end{array}$ & 12.64 & 12.53 & 12.60 \\
\hline $\begin{array}{l}\text { Vanmycetin } \\
\text { [FDC Ltd., India] }\end{array}$ & 12.64 & 12.55 & 12.60 \\
\hline
\end{tabular}

a. Average of five determinations

Table 5 Determination of mercury(II) in ayurvedic medicines

\begin{tabular}{|l|l|l|l|}
\hline Sample & $\begin{array}{l}\text { Certified value of mercury } \\
(\mu \mathrm{g} / \mathrm{ml})\end{array}$ & $\begin{array}{l}\text { Mercury found by PAHB } \\
\operatorname{method}^{\mathrm{a}}(\mu \mathrm{g} / \mathrm{ml})\end{array}$ & $\begin{array}{l}\text { Mercury found by PAN } \\
\text { method }(\mu \mathrm{g} / \mathrm{ml})\end{array}$ \\
\hline $\begin{array}{l}\text { Ras Sindur } \\
\text { [Shree Baidyanath Ayurved Bhavan } \\
\text { Ltd., India] }\end{array}$ & ---- & 141 & 140 \\
\hline $\begin{array}{l}\text { Siddha makardhwaj } \\
\text { [Dabur India ltd.] }\end{array}$ & ----- & 109 & 110 \\
\hline
\end{tabular}

a. Average of five determinations

\section{Figure Captions}

Fig. 1 Possible complex formation.

Fig. 2 Absorption spectra of PAHB and $\mathrm{Hg}(\mathrm{II})-\mathrm{PAHB}$ in toluene.

Fig. 3 Extraction of $\mathrm{Hg}(\mathrm{II})$ as function of $\mathrm{pH}$.

Fig. 4 Extraction Behavior of $\mathrm{Hg}(\mathrm{II})$ as function of PAHB concentration.

Fig. 5 Ringbom's plot.

Fig. 6 Plot of composition of the extracted species by Job's continuous variation method.

Fig. 7 Plot of composition of the extracted species by Mole ratio method.<smiles></smiles>

Fig. 1 Plausible complex formation.

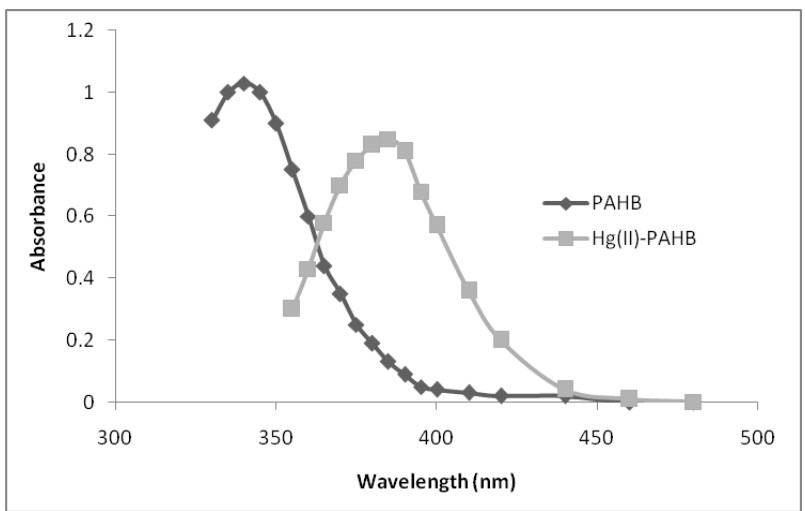

Fig. 2 Absorption spectra of PAHB and $\mathrm{Hg}$ (II)-PAHB in toluene. 


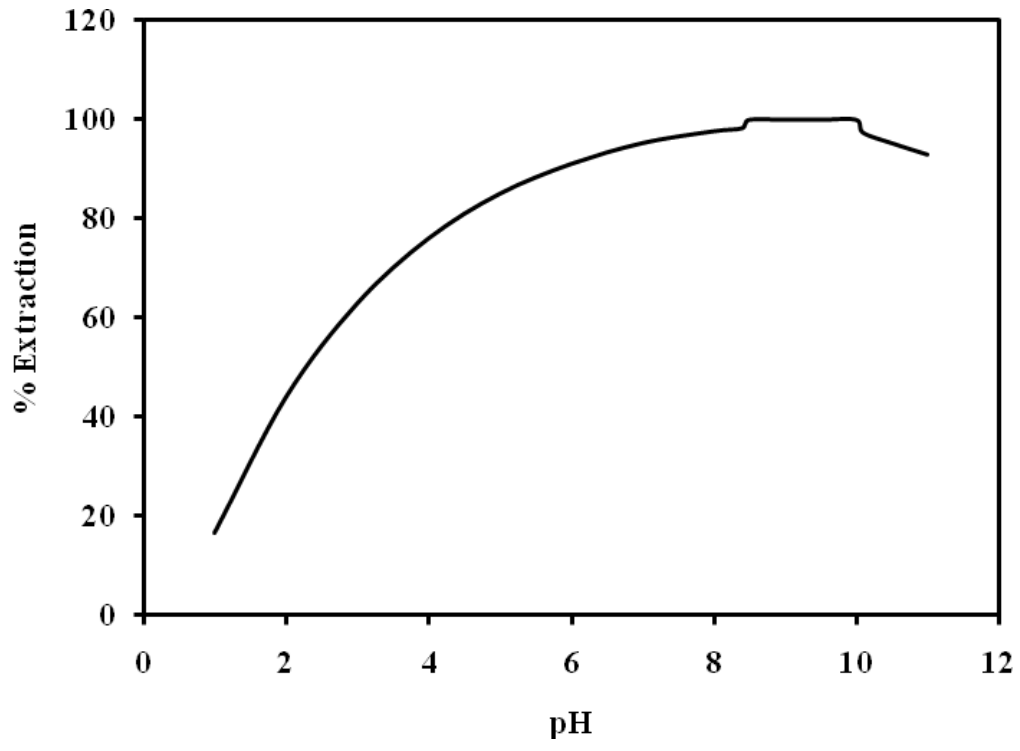

Fig. 3 Extraction of $\mathrm{Hg}(\mathrm{II})$ as function of $\mathrm{pH}$

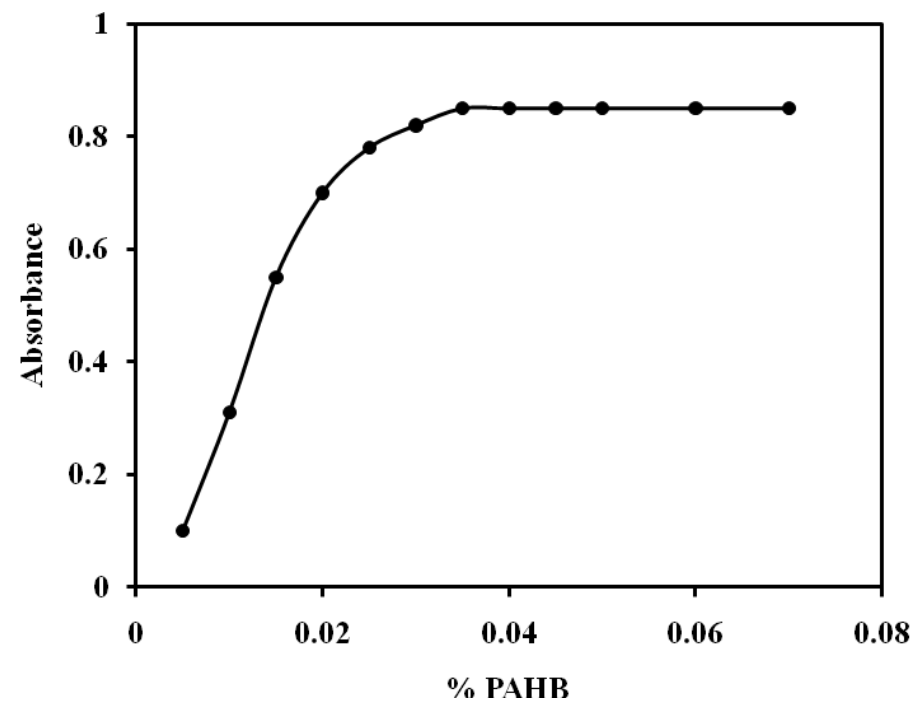

Fig. 4 Extraction Behavior of $\mathrm{Hg}(\mathrm{II})$ as function of PAHB concentration.

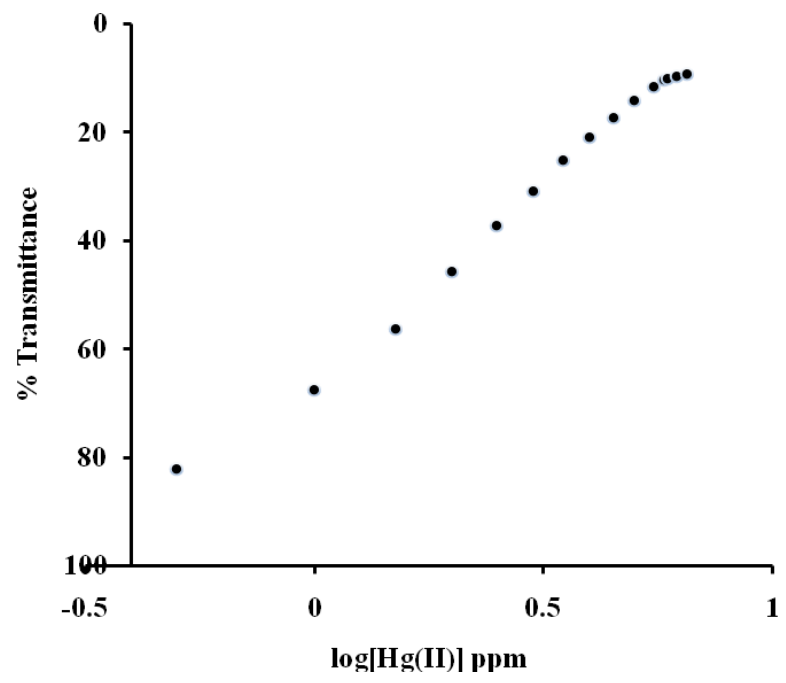

Fig. 5 Ringbom's plot. 


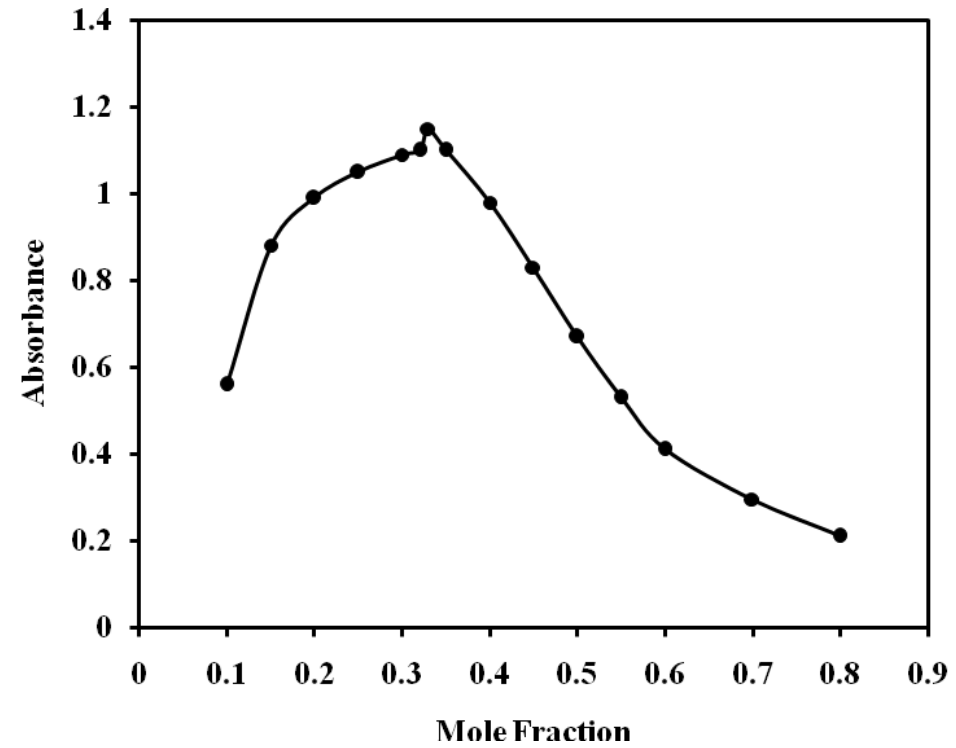

Fig. 6 Plot of composition of the extracted species by Job's continuous variation method.

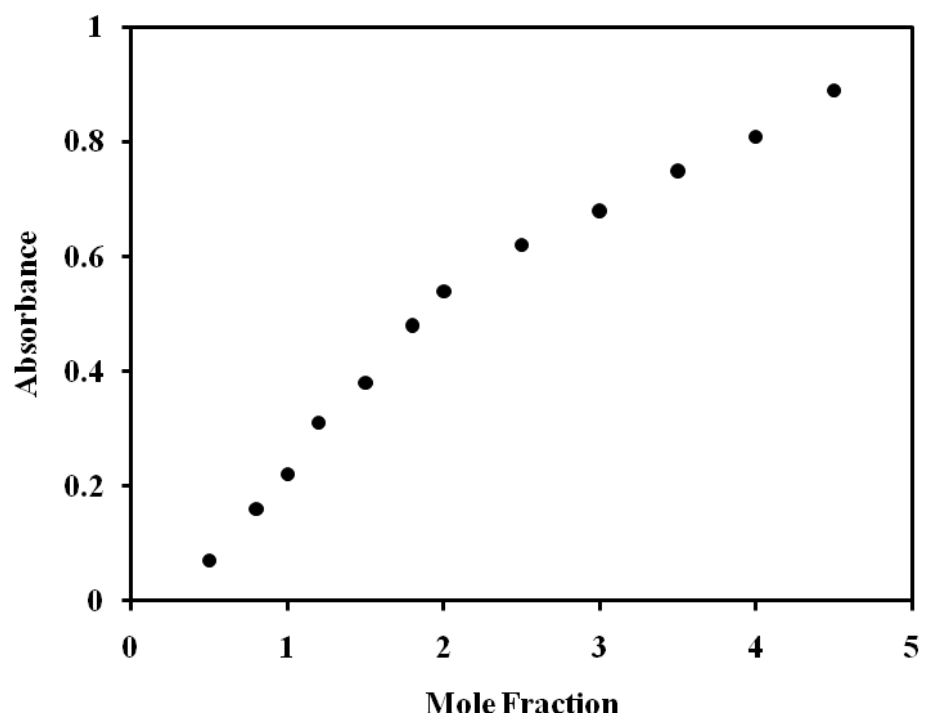

Fig. 7 Plot of composition of the extracted species by Mole ratio method. 